\title{
Getting More Out of Your Interview Data: Toward a Framework for Debriefing the Transcriber of Interviews
}

\author{
Rebecca K. Weinbaum \\ Department of Counseling and Special Populations \\ Lamar University, 223 Education Building, Beaumont, Texas 77710, USA \\ E-mail: rebecca.frels@gmail.com
}

Anthony J. Onwuegbuzie (Corresponding author)

Department of Educational Leadership and Counseling, Box 2119

Sam Houston State University, Huntsville, Texas 77341-2119, USA

Tel: 1-936-294-4509Ｅ-mail: tonyonwuegbuzie@aol.com

\begin{abstract}
Received: March 25, 2016 Accepted: April 22, 2016 Published: May 14, 2016
doi:10.5296/jei.v2i1.9216 URL: http://dx.doi.org/10.5296/jei.v2i1.9216
\end{abstract}

\begin{abstract}
In most qualitative research studies involving the creation of interview transcriptions, researchers seldom demonstrate much reflexivity about the transcription process, rarely making mention of transcription processes as part of their reporting of data collection and analysis procedures beyond a simple statement that audio- or videotaped data were transcribed. Disturbingly, although transcription is a part of the qualitative analysis process, transcription as a research method has received scant attention in the qualitative research literature. Thus, the purpose of this article was to provide a framework for debriefing the transcriber. As part of this framework, we have designed questions for the researcher to ask the transcriber to address representation and legitimation and also to facilitate movement into a deeper investigation. Finally, we present three examples of works from the extant literature wherein the transcriber was debriefed.
\end{abstract}

Keywords: Qualitative research, Interview transcribing, Credibility, Trustworthiness, Methodology, Debriefing interview 


\section{Introduction}

Getting More out of your Interview Data: Toward a Framework for Debriefing the Transcriber of Interviews

Since the 1900s, qualitative research studies primarily have involved the collection, analysis, and interpretation of nonnumeric data that naturally occur from one or more of the following four broad sources: talk (i.e., data that are obtained directly from the voices of one or more participants using data collection techniques such as individual interviews and focus groups), observations (i.e., collection of data by systematically watching or perceiving one or more events, occurrences, interactions, or nonverbal communication in order to address or to inform one or more research questions), images (i.e., still [e.g., photographs, drawings] or moving [e.g., videos] visual data that are observed or perceived), and documents (i.e., collection of text that is presented either in printed or digital form) (Leech \& Onwuegbuzie, 2008).

Of these four broad sources, the use of individual interviews represents the most common form of data collected in qualitative research studies. In support of our contention, Denham and Onwuegbuzie (2013), who examined all 401 articles published in The Qualitative Report, between 1990 and 2012, documented that $62.3 \%$ of these articles involved the collection of talk data from individual interviews. Thus, it should not be surprising that the last two decades have witnessed numerous works on the topic of interviews, including books (e.g., Brinkmann \& Kvale, 2015), handbooks (e.g., Gubrium, Holstein, Marvasti, \& McKinney, 2012), book chapters (e.g., Fontana \& Frey, 2005), journal articles (e.g., Guest, Bunce, \& Johnson, 2006; Turner, 2010), and the like. These works have provided discussions of several types of interviews such as structured interviews (i.e., standardized interviews wherein all interviewees in a study are asked the same question by the interviewer), semi-structured interviews (i.e., non-standardized interviews wherein an interview guide is used but the order of the questions can be altered depending on the direction of the interview, and additional questions can be asked for the purpose of prompting and probing), unstructured interviews (i.e., non-standardized, non-directed, and flexible interviews in which a detailed interview guide is not used and interviewees are encouraged to provide as in-depth responses as possible), and non-directive interviews (i.e., non-standardized interviews wherein questions are not usually pre-planned such that the interviewer leads the conversation and the interviewer follows what the interviewee says) (Kajornboon, 2005).

As is the case for the other three sources of qualitative data, talk data in general and interview data in particular are problematized by the three crises that Denzin and Lincoln $(2005,2011)$ identified, namely: the crisis of representation, crisis of legitimation, and crisis of praxis. With regard to the crisis of representation, an important goal in virtually all qualitative interviews is to capture authentically the (lived) experiences of people. According to Denzin and Lincoln (2005), the crisis of legitimation compels qualitative researchers to engage in "a serious rethinking of such terms as validity, generalizability, and reliability, terms already retheorized in postpositivist ... constructivist-naturalistic ... feminist ... interpretive ... poststructural ... and critical ... discourses. This crisis leads to the question, 'How are 
qualitative studies to be evaluated in the contemporary, poststructural moment?'” (pp. 19-20, italics in original). Finally, the crisis of praxis leads to the question, "Is it possible to effect change in the world if society is only and always a text?" (p. 20). As noted by Onwuegbuzie and Leech (2004),

The crises of representation, legitimation, and praxis threaten qualitative researchers' ability to extract meaning from their data. In particular, lack of representation means that the evaluator has not adequately captured the data. Lack of legitimation means that the extent to which the data have been captured has not been adequately assessed, or that any such assessment has not provided support for legitimation. Thus, the significance of findings in qualitative research is affected by these crises. (p. 778)

The crises of representation, legitimation, and praxis, then, make it important for qualitative researchers to be reflexive during the process of collecting, analyzing, and interpreting interview data. Indeed, as noted by Fontana and Frey (2005), "many studies that use unstructured interviews are not reflexive enough about the interpreting process" (p. 713), despite the promotion of reflexivity as an important means for critically evaluating the whole qualitative research process (Alvesson \& Sköldberg, 2009). According to Alvesson and Sköldberg (2009), reflexivity typically involves the "complex relationship between process of knowledge production and the various contexts of such processes, as well as the involvement of the knowledge producer" (p. 8).

Thus, in an effort to promote reflexivity during the interview process, two sets of researchers independently have developed a formalized and structured form of peer debriefing, which involves a peer debriefer formally interviewing the researcher at multiple phases of the study, a process known as interviewing the (interpretive) researcher (Onwuegbuzie, Leech, \& Collins, 2008) or interviewing the investigator (Chenail, 2011). Chenail (2011) contended that the interviewing the investigator technique uniquely helps the researcher to appreciate what it feels like to be a participant in the research study, which, in turn, can yield potentially more ethical and culturally responsive research.

Encouragingly, the use of debriefing interviews has been found to be extremely effective for enhancing reflexivity (cf. Frels \& Onwuegbuzie, 2012). However, one type of debriefing interview that has been totally neglected in the qualitative research literature is that of the transcriber. Because, as Agar (1996) stated, "Transcription is a chore" (p. 153), and, moreover, can be extremely time consuming (Gravois, Rosenfield, \& Greenberg, 1992)—which can affect both the turnaround time for disseminating findings emanating from the interview data (Bertrand, Brown, \& Ward, 1992) and even whether the taped interview data actually will be analyzed (Gravois et al., 1992) — an increasing number of qualitative researchers are relying on transcription services, paying professionals or even non-professionals (e.g., relatives, friends, other researchers, fellow students) to transcribe their interview data. And because a transcript represents an interpretation that is constructed by the transcriber (Lapadat \& Lindsay, 1999; Mishler, 1991), it is essential that qualitative researchers are reflexive about how transcribers represent the participant interview data, as well as their positionality as transcribers in their respective research studies. Yet, in the vast majority of qualitative 
research studies that involve the creation of interview transcriptions, researchers seldom demonstrate much reflexivity about the transcription process, rarely making mention of transcription processes as part of their reporting of data collection and analysis procedures beyond a simple statement that audio- or videotaped data were transcribed (Lapadat \& Lindsay, 1999). In particular, qualitative researchers have been largely unreflective about (a) "the theoretical and methodological implications of using transcriptions" in general (Lapadat \& Lindsay, 1999, p. 77) and (b) transcriptions that are not constructed by the researchers in particular. And although the transcription process might not represent the more exciting component of the qualitative research process, it should be recognized that it is a pivotal component of any qualitative research study in which interviews are conducted (Oliver, Serovich, \& Mason, 2005). Disturbingly, although transcription is a part of the qualitative analysis process, transcription as a research method has received scant attention in the qualitative research literature. With this gap in the qualitative research literature in mind, the purpose of this article is to provide a framework for debriefing the transcriber.

\section{Philosophical Framework}

Onwuegbuzie and Frels (2013) introduced a research philosophy that they referred to as critical dialectical pluralism, which is based on the assumption that social injustices prevail at all levels of society. According to these methodologists, the broad goal of critical dialectical pluralists is to conduct research that advances and sustains an egalitarian society, to promote both universalistic theoretical knowledge and local practical knowledge, and to conduct research that is culturally progressive. Critical dialectical pluralism is distinct from other transformation-based research philosophies that are centered on social justice (e.g., critical theory, critical race theory, critical quantitative research, feminist theory) by also focusing on the (potential) social injustice that is perpetuated - often unwittingly-by researchers on their participants as a result of researchers exclusively making methodological decisions at every stage of the research process. To address this social injustice, when conducting research studies, critical dialectical pluralists make every effort to empower participants to make research-based decisions at as many stages of the research process as possible-namely, at the research conceptualization, research planning, research implementation, research dissemination, and research utilization stages of the research process. Critical dialectical pluralists promote this laissez-faire style of research by adopting a research-facilitator role that allows participants to serve as participant-researchers who meta-ethically co-construct knowledge and then disseminate and utilize the findings themselves, or with the research-facilitator(s), in a format of their choice.

Our notion of debriefing the transcriber then is an extension of critical dialectical pluralism wherein whenever the qualitative researchers ask someone else to transcribe their data, the transcriber, by virtue of undergoing debriefing interviews, is transformed into a co-participant in the research study (i.e., co-researcher) to some degree — as advocated by Tilley (2003).

\section{Methodological Framework}

In this article, we build on Onwuegbuzie et al.'s (2008) framework for debriefing research participants. Interviewing the transcriber adds trustworthiness to the transcription process by 
identifying thoughts, perceptions, feelings, and experiences of the transcriber, which, in turn, facilitates the researcher in moving deeper into the investigation and capturing participants' voices to a greater extent. As part of our transcriber debriefing framework, we have designed questions for the researcher to ask the transcriber to address representation and legitimation and also to facilitate movement into a deeper investigation. The debriefing interview questions also have been designed to validate technical and thematic components of the study. Table 1 presents questions and topics for interviewing the transcriber. As seen in Table 1, the researchers' intent in conducting debriefing interviews is to recognize not only the impact of the study on participants, stakeholders, and the researcher, but also to recognize both the impact of the transcriber on the study and the impact of the study on the transcriber.

Table 1. Possible debriefing topics and questions relating directly to transcriber's perceptions

\begin{tabular}{|c|c|c|}
\hline Goal of Question & Topic & Question \\
\hline Representation & Quality of recordings & $\begin{array}{l}\text { What is your opinion regarding the recording quality } \\
\text { (e.g., sound technology) of the interviews? } \\
\text { How easy or difficult was it to understand the interviews } \\
\text { regarding accent, style, speech patterns, pace, or any } \\
\text { other interactive elements? } \\
\text { How easy or difficult was it to understand the content } \\
\text { that was delivered? }\end{array}$ \\
\hline Representation & Interpretation of interviews & $\begin{array}{l}\text { Is there anything in particular that stands out to you } \\
\text { about the interviews? } \\
\text { Looking back to when you transcribed the interviews, } \\
\text { what positive thoughts come to mind? } \\
\text { Looking back to when you transcribed the interviews, } \\
\text { what negative thoughts come to mind? }\end{array}$ \\
\hline Representation & Impact on the transcriber & $\begin{array}{l}\text { Is there any particular interview that impacted you and if } \\
\text { so how? } \\
\text { Is there any particular interview that surprised you and if } \\
\text { so how? }\end{array}$ \\
\hline Representation & Impacts on the transcriber & $\begin{array}{l}\text { In what ways, if any, do you feel you are a different } \\
\text { person now that you have transcribed these interviews? } \\
\text { In what ways, if any, do you feel your } \\
\text { gender/race/culture/class/status/age influenced your } \\
\text { thoughts about the interviews? } \\
\text { What experiences have you had that you believe } \\
\text { impacted your thoughts regarding these interviews? }\end{array}$ \\
\hline
\end{tabular}




\section{Ethics of Conducting Transcriber Debriefing Interviews}

Because interviewing the transcriber involves the collection of (qualitative) data, this step in the qualitative research process should be documented as part of the application for Institutional Review Board (IRB) approval for the overall qualitative research study. In this way, transcriber debriefing interviews would be IRB-approved, thereby increasing the ethicalness of these interviews. In fact, as critical dialectical pluralists, we believe that, regardless of whether the transcriber is interviewed, whenever transcribers are used, the transcription process should be included as part of the application for IRB approval for the overall study because transcribers will have access to all, or at least part, of the data (e.g., audio-recording) collected via interviews (e.g., individual interviews, focus group interviews). Thus, we are both surprised and concerned that many qualitative researchers do not acknowledge to IRB committees the fact that the transcriber will have such access to the data; and some researchers even go so far as to declare to IRB committees that "only members of the research team will have access to the data" and fail to document the transcriber's access to these data. Indeed, we believe that this omission raises an ethical concern. Thus, we recommend strongly that IRB approval always be sought not only to interview transcribers but also to enlist transcribers to transcribe interview data.

\section{Heuristic Example of a Transcriber Debriefing}

As part of our demonstration of the utility of transcriber debriefings, we present two examples of a published work wherein the transcriber was debriefed. Both of these examples highlight the utility of conducting debriefing interviews.

\subsection{Heuristic Example 1}

First, we showcase the work of Frels (2010) who conducted a qualitative, collective case study (cf. Stake, 2005) in order (a) to explore selected mentors' perceptions and experiences of the dyadic mentoring relationship in school-based mentoring; and (b) to understand the roles, purposes, approaches, and experiences of the relationship process with mentees (i.e., the dyadic relationship). Frels (2010) addressed the following research questions:

1) What are the perceptions of selected school-based mentors of the dyadic relationship?

2) What are the experiences of selected school-based mentors with the dyadic relationship?

3) What are the perceptions of selected school-based mentors regarding roles, purposes, and approaches of mentoring?

Further, she addressed the following subquestions:

4) What are the differences and similarities in perceptions and experiences of selected school-based mentors as a function of the gender of the mentor?

5) What are the differences and similarities in perceptions and experiences of selected school-based mentors as a function of the ethnicity of the mentor?

6) What are the differences and similarities in perceptions and experiences of selected school-based mentors in same-gender mentee/mentor pairings versus different-gender 
mentee/mentor pairings?

7) What are the differences and similarities in perceptions and experiences of selected school-based mentors in same-ethnic mentee/mentor pairings versus different-ethnic mentee/mentor pairings?

To address these research questions, Frels's (2010) collective case study involved the selection of 11 adult mentors ( 4 men, 7 women), whose ages ranged from 28 to 70 years, with ethnicities of African American $(n=5)$, Hispanic $(n=2)$, and White $(n=4)$. She paired each of these mentors with a mentee in a manner that involved one of the following two mentee-mentor pairings: same-gender versus different-gender mentee-mentor pairings and same-ethnic versus different-ethnic mentee-mentor pairings.

Frels (2010) collected an array of data with regard to all dyad interactions, including a quantitative instrument, observations, descriptive case notes, reflexive data, and debriefing data. However, interviews represented her major data collection technique for exploring the phenomenon of dyadic mentoring relationships. Indeed, this form of data collection was compatible with her critical dialectical pluralist lens as a researcher and her professional identity as a school counselor. Each mentor was interviewed separately on multiple occasions, with each participant interview lasting between 20 minutes and 60 minutes. All participant interviews were semi-structured, involving questions that were purposefully created to gain insights into the experience of the dyadic relationship. Examples of participant interview questions included the following: "What are your beliefs, thoughts, and opinions about the purpose of mentoring?"; "What words, phrases, or images come to mind to describe the time you spend with your mentee?"; and "When you feel challenged in your relationship, what are some thoughts or beliefs that help?"

Because of the amount of data collected to address her research questions, Frels (2010) understandably made the decision to have interview data transcribed by another person. Once transcribed, each transcription was presented back to the respective participant via a member-checking interview that lasted between 20 minutes and 60 minutes to review for accuracy, adequacy, and, above all, authenticity - thereby enhancing descriptive validity (i.e., the factual accuracy and adequacy of the account as documented by the researcher; Maxwell, 1992). As declared by Manning (1997), "thorough member checking, including respondent review of field notes, working hypotheses, and case study drafts, means that the researcher is accountable to those sharing their words, lives, and experiences" (p. 102). Further, according to Cho and Trent (2006), transactional validity is "an interactive process between the researcher, the researched, and the collected data that is aimed at achieving a relatively higher level of accuracy and consensus by means of revisiting facts, feelings, experiences, and values or beliefs collected and interpreted" (p. 321). Also, transformative validity is "a progressive, emancipatory process leading toward social change that is to be achieved by the research endeavor itself" (Cho \& Trent, 2006, pp. 321-322). Thus, an additional goal of Frels's (2010) member-checking interviews was to enhance both transactional validity and transformative validity.

For the transcriber debriefing interview, the questions asked included those in Table 1. In 
asking these questions, the goal was to address representation and legitimation and also to generate thicker and richer data (Geertz, 1973). With respect to the category of representation through quality of recordings, the transcriber reported that the recording quality on a scale from 1 to 10 was excellent and at a 9.5. Further, he disclosed his interpretation of the participant interviews to be positive, with only one case standing out in his mind as being different from the others. Particularly motivating for him when interpreting the participant interviews was that,

They [mentors] go with an open mind, and... they look just to make a day better, make it easier on them [mentees]. And they don't look for any sort of compensation or recognition for it. It's just doing something nice for somebody in the world.

Further, he noted a type of goodness inherent in the study that impacted him relating to his own experiences:

I guess coming from a family that has been very nurturing and also very community oriented $>$ it has impacted me in a way such that (.) it makes me appreciate people for what they do again. I guess that's the only, that's the main thing that I got out of it you know. I really appreciate what these people do and it makes me want to do it. It reminds me of (.) you know (.) when I worked at the boys and girls club with the little kids, or volunteering $\downarrow$ I don't know.

Perceptions of non-verbal communication were most revealing with the respect to the way that Frels (2010) interpreted data. For example, she integrated in her analysis as outlined by Gorden (1980), four basic modes during the debriefing interviews: (a) proxemic, the use of interpersonal space to communicate ideas; (b) chronemic, the way speech and silence is conveyed through conversation; (c) kinesic, the body movements or postures; and (d) paralinguistic, the variations in volume, pitch, and quality of voice. These modes were confirmed through the transcriptions as the transcriber detected the auditory tone of the participant interviews. The following example of the transcriber debriefing interview revealed what Frels $(2010$, p. 21) referred to as a "two-way interactive transformative-emancipatory stance" (i.e., a stance - representing both mentees and mentors who are at risk for dropping out of mentoring relationships - that is driven by the researcher who aims to conduct research that is emancipatory, participatory, and antidiscriminatory, and who focuses directly on the lives and experiences of underserved, under-represented, and marginalized persons or groups such as women; ethnic/racial/cultural minorities; individuals with disabilities/exceptionalities; and members of gay, lesbian, bisexual, and transsexual communities; Mertens, 2007):

I could feel sometimes (.) not feel- hear a definite connection between you and the interviewee (...) but I didn't know how the setup was. I could just feel there was more than just words being exchanged $<$ there was an emotion being portrayed. Like sometimes you would ask the mentor (.) umm, about something and you could hear them become overwhelmed with a certain feeling of joy or excitement, whenever you ask about what they like best about it (.) you could hear the smile come on their face. So that was interesting and there were also times where they would tell the story and you'd hear 'oh let me tell you about this'. It seems like (.) they would be expressing themselves not 
only verbally but physically but I could see where there could be contact between you and the mentor occasionally.

With respect to saturation, it was revealed through the transcriber debriefing interview that saturation was met through the 33 observations and 11 participant interviews. The transcriber stated,

I think if you were to do more you would reinforce that idea [pleasure with the mentee]. Umm, also all of them said that it's a time commitment and you can't quit on the kids. So (...) I think there are some of the common themes you see no matter who you interview how many times. That would pop up as one of the main things that each one of them said.

Finally, addressing his own perceptions regarding the participant interview data, he revealed the following:

[laughter] I don't know how these people do it $\uparrow$ I guess because it's only once a week (.) but when I worked at the boys and girls club, I got headaches every day because I went there every day but I don't know (...) it just can be frustrating but you do have to go in with an open mind or else you're going to go crazy and the fact that these people do it every week of the school year... is ridiculous, ridiculously awesome.

In conclusion, the transcriber debriefing interview helped Frels (2010) to operate as a focused researcher acting within the axiological principals of respect, beneficence, and justice (Mertens, 2007).

\subsection{Heuristic Example 2}

As a second example, we briefly describe the transcriber debriefing interview that occurred during the series of mixed research studies conducted by Rebecca Frels, Anthony J. Onwuegbuzie, and colleagues (Frels, Onwuegbuzie, Leech, \& Collins, 2012, 2014; Onwuegbuzie, Frels, Leech, \& Collins, 2011, 2013) examining the teaching and learning context in doctoral-level mixed research courses, including pedagogical strategies used by select leading mixed methodologists in mixed research courses, challenges to teaching mixed research courses, and student learning in mixed research courses. On account of the number of interviews involved in these studies, all the participant interviews were transcribed by another person. These researchers subsequently interviewed the transcriber.

Because the transcriber was able to listen to the audio-recordings of each participant interview, he was able to provide valuable insights into the nonverbal communication behavior exhibited by each research participant, particularly the following: chronemics (i.e., use of pacing of speech and length of silence in conversation), kinesics (i.e., body movements or postures), paralinguistics (i.e., all variations in volume, pitch, and quality of voice), linguistics (i.e., language form [e.g., morphology, syntax, phonology, phonetics], of language meaning [i.e., semantics, pragmatics], and/or of language in context [e.g., evolutionary linguistics, historical linguistics, sociolinguistics, psycholinguistics, neurolinguistics, language acquisition, discourse analysis]). (For a detailed discussion of nonverbal 
communication, see Denham \& Onwuegbuzie, 2013; Onwuegbuzie \& Byers, 2014; Onwuegbuzie \& Frels, 2012.) For example, the transcriber discussed his perceptions that arose while transcribing each set of participant interviews regarding those research participants who displayed the most passion for teaching mixed methods research courses during the participant interviews, as well as those who appeared to be the most innovative and reflective. Also, the transcriber provided the researchers with excellent recommendations such as the researchers in future mixed methods research studies providing transcribers with a glossary of terms and concepts that are specific to mixed methods research (e.g., quantitizing; which involves converting qualitative data into numerical codes that can be analyzed statistically; Miles \& Huberman, 1994; Onwuegbuzie \& Teddlie, 2003; Sandelowski, Voils, \& Knafl, 2009; Tashakkori \& Teddlie, 1998) so that the transcribers would know how to spell these research-based words in their transcriptions as they are mentioned by the research participants. Thus, as illustrated by the previous heuristic example, in this study, the transcriber debriefing interview led to enhanced representation and legitimation of the original interview data.

\subsection{Heuristic Example 3}

As part of an ongoing research effort at one university, a mentor group was established with the goal of working with underrepresented to increase minority representation in master's-level training. This mentor program enlisted graduate students to meet with selected minority undergraduate students with the goal of increasing engagement in their coursework and increasing connectedness to the university. The mentoring program training for mentors focused on leadership, education, advocacy, and diversity. This mentoring program was designed as an intersect between (a) the goal of relieving the limited numbers for underrepresented minorities and (b) the building of a positive cultural climate, which involved examining biases and ways in which color blindness might perpetuate ethnic inequities.

Throughout the year, mentors met bi-weekly in small groups to participate in diversity trainings. The qualitative tools utilized for data collection were reflexive journals, a mid-term reflection paper, mentor focus group interviews, and individual mentee interviews. At the end of Year 1, the reflexive journals were transcribed, analyzed, and interpreted by a selected undergraduate student (African American female), who served as a research assistant. Also, at the end of Year 1, mentors participated in four focus group meetings, whereby they co-constructed questions about the program of which they deemed important to address. These focus groups also were transcribed, analyzed, and interpreted by the undergraduate research assistant and the co-researcher working with mentors.

Selecting a Transcriber: The primary investigators in the research recognized how their own experiences and culture might limit their interpretations of the data collected with respect to diversity trainings. Also, they recognized the power distribution and implications of being university instructors interviewing graduate students. The program directors enlisted an African American undergraduate student as a research assistant, who transcribed hand-written journals and interview data. In this case, selecting a transcriber with intention increased the 
credibility and usefulness of data interpretations and impact of the mentor program in three ways. First, it allowed investigators the opportunity to help an undergraduate student learn the qualitative research process, inclusive of data analysis and interpretation steps. Second, the transcriptions became an opportunity to engage in honest dialogue with one African American undergraduate student about nuances in the data, which could be translated into future dialogue with mentors and more focused data. Finally, it addressed one challenge relating to the use of a critical dialectical pluralism stance, which, as noted previously, yields research that aims to promote an egalitarian society for both universalistic theoretical knowledge and local practical knowledge (Onwuegbuzie \& Frels, 2013). This challenge related to how attitudes about social justice could be deeply engrained in participants. Having an undergraduate African American student serving as the transcriber helped to mediate some uncomfortable dialogue for both program coordinators and mentors alike. In short, defenses and attitudes could be transformed into honest expressions for learning.

The research assistant as transcriber worked closely with the principle investigator who facilitated trainings with mentors and was debriefed on three occasions during the data collection process. In addition, she was asked to use memos to document her own thoughts and feelings associated with transcribing data. Figure 1 depicts some of her ideas during the transcription process of mentor journals.

\footnotetext{
Journal Entry of Mentor 1

These classes can be frustrating for me because I do not agree with the "anything goes" because it promotes diversity mindset. I believe there is a right and wrong. I also have a tendency to get annoyed with how things should be different for people of different races. I'm white and you're black so what...let's be friends. I would want to help anyone anywhere of any status-because we are all humans and are so much more alike than we realize. With that being said I do not appreciate being stereotyped myself as someone with "white privilege."

This was very powerful. She impresses me as an advocate for peace and kindness. Does she realize that in order to reach these ideals the issue of difference must first be discussed? Do the discussion make her uncomfortable?
}

Figure 1. Example of a mentor journal and the memo made by the transcriber

After debriefing the transcriber and much reflection, categories were revisited to understand interrelationships between professional identity and context, as it related to the training modules in cultural competence. Selective coding for the core categories facilitated how the final theory began to emerge - which was built on the iterative concepts of wanting ethnicity to be a non-variable in their field, which was expressed in numerous ways. Theoretical coding yielded insight into two areas: (a) the unique setting of a college campus and cultural exchanges and (b) the various layers that represented how graduate students expressed their 
desire for equity with respect to minority opportunities in their profession. A debriefing interview with the transcriber helped to identify some primary categories, which, in turn, led to the next round of coding for greater focus on subtleties within the data. As a result, program coordinators developed a new approach for the second year of mentor training whereby notions of inequity were discussed as relating to privilege and oppression rather than ethnicity and diversity.

\section{Conclusions}

Two decades ago, Poland (1995) called for qualitative researchers to become more reflective about their transcription procedures, especially because transcripts are constructed texts. Unfortunately, for the most part, this lack of reflexivity of the transcription appears to remain, likely stemming from the lack of guidance in the qualitative research literature on the transcription process. And because the process of transcribing includes analysis at some level (Kvale, 1996), and that "all transcription is in some sense interpretation" (Cook, 1990, p. 12), reflexivity is even more important when the transcriber is someone other than the researcher. Thus, we have provided a framework for increasing reflexivity in these situations via the researcher conducting IRB-approved debriefing interviews on the transcriber, thereby transforming transcription as a research method.

Debriefing the transcriber aligns with Ball's (2012) foundational [reflective] practices for expanding perspective for: (a) thoughtful reflection for "metacognitive awareness concerning the critical role of the need for cooperation among researchers, policy-makers, and practitioners" (p. 288); (b) introspection, which involves the researcher looking at personal qualities as a pathway to increased advocacy - specifically revealed through knowledge integration, and collaboration to impact practices and policies; (c) critique of any static levels of knowledge and practices in which research knowledge is being consumed or not consumed and (d) personal voice, which is acquired through inspection of the findings and how they are translated into practice. In fact, by incorporating the reflective practices after debriefing interviews, social and educational researchers can better address what is referred in the health science fields as translational research (Nastasi \& Hitchcock, 2009; National Institute of Health, n.d.; Newman, Hitchcock, \& Nastasi, 2013).

As seen from the three heuristic examples, not only do these IRB-approved transcriber debriefing interviews enhance what Poland (1995) referred to as the "trustworthiness of transcripts as research data" (p. 294), but also they provide an audit trail for the transcription process. Consequently, the use of IRB-approved transcriber debriefing interviews is consistent with the two overarching principles characterizing the American Educational Research Association's (AERA's) standards for reporting on empirical social science research, namely, that research reports should be (a) warranted, that is, adequate evidence should be provided to justify the results and conclusions); and (b) transparent, that is, reporting should make explicit the logic of inquiry and activities that led from the development of the initial interest, topic, problem, or research question; through the definition, collection, and analysis of data or empirical evidence; to the articulated outcomes of the study (AERA, 2006, p. 33 ) - with both elements adding rigor to the qualitative research process. And, as noted by 
AERA (2006), "Reporting that takes these principles into account permits scholars to understand one another's work, prepares that work for public scrutiny, and enables others to use that work" (p. 33)—-thereby advancing Onwuegbuzie and Frels's (2016, pp. xiii-xiv) call for researchers to adopt an approach that is culturally progressive (i.e., operating under the assumption that "knowledge sources stem from people [i.e., participants] and are generated by people [i.e., researchers, authors] who represent all cultures, races, ethnic backgrounds, languages, classes, religions, and other diversity attributes"-including transcribers), ethical (i.e., maximizing integrity, scholarly responsibility, social responsibility, and respecting rights, dignity, and diversity of all co-participants in the research study-including transcribers), and multimodal (i.e., examining various modes of data-including data stemming from transcribers).

\section{References}

Agar, M. (1996). The professional stranger: An informal introduction to ethnography. New York, NY: Academic Press.

Alvesson, M., \& Sköldberg, K. (2009). Reflexive methodology: New vistas for qualitative research (2nd ed.). London, England: Sage.

American Educational Research Association. (2006). Standards for reporting on empirical social science research in AERA publications. Educational Researcher, 35(6), 33-40.

Ball, A. F. (2012). To know is not enough: Knowledge, power, and the zone of generativity. Educational Researcher, 41, 283-293. http://dx.doi.org/10.3102/0013189X12465334

Bertrand, J. T., Brown, J. E., \& Ward, V. M. (1992). Techniques for analyzing focus group data. Evaluation Review, 16, 198-209. http://dx.doi.org/10.1177/0193841X9201600206

Brinkmann, S., \& Kvale, S. (2015). Interviews: Learning the craft of qualitative interviewing. Thousand Oaks, CA: Sage.

Chenail, R. J. (2011). Interviewing the investigator: Strategies for addressing instrumentation and researcher bias concerns in qualitative research. The Qualitative Report, 16(1), 255-262. Retrieved from http://www.nova.edu/ssss/QR/QR16-1/interviewing.pdf

Cho, J., \& Trent, A. (2006). Validity in qualitative research. Qualitative Research, 6, 319-340. http://dx.doi.org/10.1177/1468794106065006

Cook, G. (1990). Transcribing infinity: Problems of context representation. Journal of Pragmatics, 14, 1-24.

Denham, M. A., \& Onwuegbuzie, A. J. (2013). Beyond words: Using nonverbal communication data in research to enhance thick description and interpretation. International Journal of Qualitative Methods, 12, 670-696. Retrieved from http://ejournals.library.ualberta. ca/index.php/IJQM/article/view/19271

Denzin, N. K., \& Lincoln, Y. S. (2005). The discipline and practice of qualitative research. In N. K. Denzin \& Y. S. Lincoln (Eds.), Handbook of qualitative research (3rd ed., pp. 1-32). 
Thousand Oaks, CA: Sage.

Denzin, N. K., \& Lincoln, Y. S. (2011). Introduction: The discipline and practice of qualitative research. In N. K. Denzin \& Y. S. Lincoln (Eds.), Sage handbook of qualitative research (4th ed., pp. 1-25). Thousand Oaks, CA: Sage.

Fontana, A., \& Frey, J. H. (2005). The interview: From neutral stance to political involvement. In N. K. Denzin \& Y. S. Lincoln (Eds.), The Sage handbook of qualitative research (2nd ed., pp. 695-727). Thousand Oaks, CA: Sage.

Frels, R. K. (2010). The experiences and perceptions of selected mentors: An exploratory study of the dyadic relationship in school-based mentoring (Unpublished doctoral dissertation, Sam Houston State University, Huntsville, TX, USA).

Frels, R. K., \& Onwuegbuzie, A. J. (2012). Interviewing the interpretive researcher: An impressionist tale. The Qualitative Report, 17(Art. 60), 1-27. Retrieved from http://www.nova.edu/ssss/QR/QR17/frels.pdf

Frels, R. K., Onwuegbuzie, A. J., Leech, N., \& Collins, K. M. T. (2012). Challenges to teaching mixed research courses. The Journal of Effective Teaching, 12, 23-44.

Frels, R. K., Onwuegbuzie, A. J., Leech, N., \& Collins, K. M. T. (2014). Pedagogical strategies used by selected leading mixed methodologists in mixed research courses. The Journal of Effective Teaching, 14(2), 5-34.

Geertz, C. (1973). Thick description toward an interpretive theory of culture. In C. Geertz (Ed.), The interpretation of cultures (pp. 3-30). New York, NY: Basic Books.

Gorden, R. I. (1980). Interview strategy techniques and tactics. Homewood, IL: Dorsey.

Gravois, T., Rosenfield, S., \& Greenberg, B. (1992). Establishing reliability for coding implementation concerns of school-based teams from audiotapes. Evaluation Review, 16, 562-569. http://dx.doi.org/10.1177/0193841X9201600507

Gubrium, J. F., Holstein, J., Marvasti, A. B., \& McKinney, K. D. (2012). The Sage handbook of interview research: The complexity of the craft. Thousand Oaks, CA: Sage.

Guest, G., Bunce, A., \& Johnson, L. (2006). How many interviews are enough? An experiment with data saturation and variability, Field Methods, 18, 59-82. http://dx.doi.org/ $10.1177 / 1525822 \times 05279903$

Kajornboon, A. B. (2005). Using interviews as research instruments. Retrieved from http:/hsmi.psu.ac.th/upload/forum/Annabelinterviewguide.pdf

Kvale, S. (1996). InterViews: An introduction to qualitative research interviewing. Thousand Oaks, CA: Sage.

Lapadat, J., \& Lindsay, A. (1999). Transcription in research and practice: From standardization of technique to interpretive positioning. Qualitative Inquiry, 5, 64-86. http://dx.doi.org/10.1177/107780049900500104 
Leech, N. L., \& Onwuegbuzie, A. J. (2008). Qualitative data analysis: A compendium of techniques and a framework for selection for school psychology research and beyond. School Psychology Quarterly, 23, 587-604. http://dx.doi.org/10.1037/1045-3830.23.4.587

Manning, K. (1997). Authenticity in constructivist inquiry: Methodological considerations without prescription. Qualitative Inquiry, 3, 93-115. http://dx.doi.org/10.1177/107780049700 300105

Maxwell, J. A. (1992). Understanding and validity in qualitative research. Harvard Educational Review, 62, 279-299.

Mertens, D. (2007). Transformative paradigm: Mixed methods and social justice. Journal of Mixed Methods Research, 1, 212-225. http://dx.doi.org/10.1177/1558689807302811

Miles, M., \& Huberman, A. M. (1994). Qualitative data analysis: An expanded sourcebook (2nd ed.). Thousand Oaks, CA: Sage.

Mishler, E. G. (1991). Representing discourse: The rhetoric of transcription. Journal of Narrative and Life History, 1, 255-280. http://dx.doi.org/10.1075/jnlh.1.4.01 rep

Nastasi, B. K., \& Hitchcock, J. H. (2009). Challenges of evaluating multi-level interventions. American Journal of Community Psychology, 43, 360-376.

National Institute of Health. (n.d.). Office of Intramural Training \& Education. Retrieved from https://www.training.nih.gov/mentoring_guidelines

Newman, I., Hitchcock, J., \& Nastasi, B. (2013). Using phenomenological principles to assess stakeholders' perceptions of probability: Applying mixed methods in translational research. Presented at the annual meeting of the American Educational Research Association, San Francisco, CA.

Oliver, D. G., Serovich, J. M., \& Mason, T. L. (2005). Constraints and opportunities with interview Transcription: Towards reflection in qualitative research. Social Forces, 84(2), 1273-1289. http://dx.doi.org/10.1353/sof.2006.0023

Onwuegbuzie, A. J., \& Byers, V. T. (2014). An exemplar for combining the collection, analysis, and interpretations of verbal and nonverbal data in qualitative research. International Journal of Education, 4(1), 183-246. http://dx.doi.org/10.5296/ije.v6i1.4399

Onwuegbuzie, A. J., \& Frels, R. K. (2013). Introduction: Toward a new research philosophy for addressing social justice issues: Critical dialectical pluralism 1.0. International Journal of Multiple Research Approaches, 7, 9-26. http://dx.doi.org/10.5172/mra.2013.7.1.9

Onwuegbuzie, A. J., \& Frels, R. K. (June, 2012). A mixed research framework for collecting and analyzing nonverbal communication data in interviews. Paper presented at the International Mixed Methods Conference, Leeds, England.

Onwuegbuzie, A. J., \& Frels, R. K. (2016). Seven steps to a comprehensive literature review: A multimodal and cultural approach. London, England: Sage. 


\section{Macrothink}

Onwuegbuzie, A. J., Frels, R. K., Leech, N. L., \& Collins, K. M. T. (2011). A mixed research study of pedagogical approaches and student learning in doctoral-level mixed research courses. International Journal of Multiple Research Approaches, 5, 169-199. http://dx.doi.org/10.5172/mra.2011.5.2.169

Onwuegbuzie, A. J., Frels, R. K., Leech, N. L., \& Collins, K. M. T. (2013). Conclusion: A four-phase model for teaching and learning mixed research. International Journal of Multiple Research Approaches, 7, 122-168. http://dx.doi.org/10.5172/mra.2013.7.1.133

Onwuegbuzie, A. J., \& Leech, N. L. (2004). Enhancing the interpretation of "significant" findings: The role of mixed methods research. The Qualitative Report, 9, 770-792. Retrieved from http://www.nova.edu/ssss/QR/QR9-4/Onwuegbuzie.pdf

Onwuegbuzie, A. J., \& Leech, N. L., \& Collins, K. M. T. (2008). Interviewing the interpretive researcher: A method for addressing the crises of representation, legitimation, and praxis. International Institute for Qualitative Methodology, 7, 1-17.

Onwuegbuzie, A. J., \& Teddlie, C. (2003). A framework for analyzing data in mixed methods research. In A. Tashakkori \& C. Teddlie (Eds.), Handbook of mixed methods in social and behavioral research (pp. 351-383). Thousand Oaks, CA: Sage.

Poland, B. D. (1995). Transcription quality as an aspect of rigor in qualitative research. Qualitative Inquiry, 1, 290-310. http://dx.doi.org/10.1177/107780049500100302

Sandelowski, M., Voils, C. I., \& Knafl, G. (2009). On quantitizing. Journal of Mixed Methods Research, 3, 208-222. http://dx.doi.org/10.1177/1558689809334210

Stake, R. E. (2005). Qualitative case studies. In N. K. Denzin \& Y. S. Lincoln (Eds.), The Sage handbook of qualitative research (3rd ed., pp. 443-466). Thousand Oaks, CA: Sage.

Tashakkori, A., \& Teddlie, C. (1998). Mixed methodology: Combining qualitative and quantitative approaches. Applied Social Research Methods Series (Vol. 46). Thousand Oaks, CA: Sage.

Tilley, S. A. (2003). Transcription work: Learning through coparticipation in research practices. International Journal of Qualitative Studies in Education, 16, 835-851. http://dx.doi.org/10.1080/09518390310001632171

Turner, D. W. III. (2010). Qualitative interview design: A practical guide for novice investigators. The Qualitative Report, 15, 754-760. Retrieved from http://www.nova.edu/ ssss/QR/QR15-3/qid.pdf 


\section{Copyright Disclaimer}

Copyright for this article is retained by the author(s), with first publication rights granted to the journal.

This is an open-access article distributed under the terms and conditions of the Creative Commons Attribution license (http://creativecommons.org/licenses/by/3.0/). 